\title{
Radiographic Outcomes of Percutaneous Pinning for Displaced Extra-Articular Fractures of the Distal Radius: A Time Course Study
}

\author{
Tien-Yu Yang, ${ }^{1}$ Yao-Hung Tsai, ${ }^{1,2}$ Shih-Hsun Shen, ${ }^{1}$ and Kuo-Chin Huang ${ }^{1,2}$ \\ ${ }^{1}$ Department of Orthopaedic Surgery, Chang Gung Memorial Hospital, 6 West Section, Chia-Pu Road, Pu-Tz City, \\ Chiayi County 613, Taiwan \\ ${ }^{2}$ Chang Gung University College of Medicine, Taoyuan 333, Taiwan
}

Correspondence should be addressed to Kuo-Chin Huang; kc2672@adm.cgmh.org.tw

Received 25 January 2014; Accepted 22 April 2014; Published 5 May 2014

Academic Editor: George Babis

Copyright @ 2014 Tien-Yu Yang et al. This is an open access article distributed under the Creative Commons Attribution License, which permits unrestricted use, distribution, and reproduction in any medium, provided the original work is properly cited.

\begin{abstract}
Introduction. Although not all malunited distal radius fractures are symptomatic, the goal of treatment for displaced extra-articular fractures of the distal radius should be to restore and to maintain the radial geometry until bone healing. However, the time course change after surgery for these fractures is unclear. Methods. We, therefore, performed a retrospective cohort study on patients who sustained such fractures treated with percutaneous pinning. The main outcome measures in this study included four radiographic measurements: radial height, radial inclination, radial tilt, and ulnar variance. Results. Assessment of the monthly changes in these measurements revealed that early fracture collapse with loss of the reduced radial tilt occurred. Besides, among the 4 measurements, the normal radial tilt was the most difficult to be achieved when repositioning and pinning the fractured fragments. Conclusions. Even though the modified Kapandji technique provided a superior ability to maintain the reduced position until bone healing over the Willenegger method, we recommended that refinement of surgical techniques and postoperative hand care program may be necessary to fulfill the treatment objectives of stable surgical fixation and early joint motion.
\end{abstract}

\section{Introduction}

Malunion of a displaced extra-articular fracture of the distal radius may affect the mechanics of the radiocarpal joint, the distal radioulnar joint (DRUJ), and the forearm axis and then result in wrist pain, motion loss, and/or decreased grip strength [1-6]. Although not all malunited distal radius fractures are symptomatic, the goal of treatment for displaced extra-articular fractures of the distal radius should be to restore and to maintain the radial geometry until bone healing. For assessing healing and predicting outcome of a distal radius fracture, Graham [7] proposed and popularized the evaluation criteria based on four familiar radiographic measurements, including radial height $(\mathrm{RH})$, radial inclination (RI), radial tilt (RT), and ulnar variance (UV). Today, Graham's criteria have become one of the most widely practiced guidelines for treatment of patients with distal radius fractures.
Clinical practice guidelines from the American Academy of Orthopaedic Surgeons (AAOS) moderately recommend stable surgical fixation, rather than cast fixation, followed by early wrist motion to treat patients with displaced distal radius fractures [8]. A key method of surgical fixation is percutaneous pinning, involving the insertion of Kirschner(K-) wires through the skin to stabilize the fracture. Although there is some evidence to support its use, the precise role and methods of percutaneous pinning are not well established [9]. Among the various methods, Kapandji and conventional pinning (Willenegger) techniques are the two most commonly used methods to treat displaced and unstable distal radius fractures without significant intra-articular displacement $[10-15]$. The main concern in percutaneous pinning for fracture fixation is the reliability of maintenance of the reduced position [13, 14, 16, 17]; however, little is known about the time course changes and patterns of fracture collapse after percutaneous pinning for displaced extra-articular fractures 
of the distal radius. This study was thus designed to evaluate the effects of two commonly used pinning techniques on the achievement and maintenance of the reduced radial geometry after fracture reduction and pin fixation for displaced extra-articular fractures of the distal radius. Our objective was to explore the time course changes of fracture collapse in these patients.

\section{Materials and Methods}

2.1. Participating Patients and Inclusion/Exclusion Criteria. The study included all adult patients with displaced extraarticular fractures of the distal radius (AO/OTA type 23A2.2 or 23-A3) who were treated with percutaneous pinning in our hospital between January 2006 and December 2009. The institutional review board of Chang Gung Memorial Hospital approved this study. We excluded patients with bilateral distal radius fractures, open or multiple fractures, underlying bone pathology, and medical problems that could severely impair bone healing and self-care ability, such as malignancies, osteomalacia, end stage renal diseases, and advanced neurodegenerative disorders.

2.2. Surgical Techniques. Two techniques of percutaneous pinning for displaced extra-articular fractures of the distal radius were regularly used in our hospital. One is the modified Kapandji technique; the other is the conventional pinning (Willenegger technique). For patients treated with the modified Kapandji technique, the reduction was performed with two intrafocal pins over a firm pad and checked under image intensification. A K-wire was inserted into the fracture site from the dorsal-ulnar side and then used to pry the distal fragment into optimal position to reestablish the palmar tilt. The other K-wire was inserted from the palmarradial side to reestablish the $\mathrm{RH}$ and the $\mathrm{RI}$. The $\mathrm{K}$-wires were then levered until the acceptable anatomy was restored, and subsequently another two K-wires were inserted through stab incisions over the radial styloid process and the dorsal-ulnar corner of the radius in a conventional manner. The ends of the last two K-wires were bent over and left percutaneously, and the first two $\mathrm{K}$-wires were removed to prevent skin indentation or tethering.

For those treated with the Willenegger technique, the reduction was facilitated and held with Chinese finger traps and checked under image intensification. After restoration of the acceptable anatomy, two small stab incisions were made over the radial styloid process and two K-wires were inserted obliquely through the styloid process from distal to proximal, with the proximal wire tip embedded and anchored in the opposite cortex of the radius. The ends of the two K-wires were bent over and left percutaneously.

Postoperative care was implemented according to a standardized regimen. The wrist was immobilized for 8 weeks in a palmar short-arm splint. In the meanwhile, active finger motion and forearm axis rotation were encouraged, but power grip even in the splint was avoided. For the next 4 weeks, physiotherapy focusing on active and passive motion exercises for the wrist and forearm was performed with the splint removed only for rehabilitation. Thereafter, the splint was discarded and power grip was permitted. Regular radiographic assessments were carried out after both procedures: they were done immediately after surgery; at one, two, three, six, and twelve months; and before and after removal of the $\mathrm{K}$-wires. The $\mathrm{K}$-wires were removed from all wrists, as outpatients, usually after six weeks.

2.3. Definition of Treatment Outcome. The main outcome measures in this study included four radiographic measurements: RH, RI, RT, and UV. RH, measured from the PA radiograph, is defined as the distance between two perpendiculars to the long axis of the radius, one drawn at the tip of the radial styloid process and the other at the ulnar corner of the lunate fossa, which averagely should be 11 to $12 \mathrm{~mm}$. RI, measured from the PA radiograph, is defined as the angle between a line joining the tip of the radial styloid process and the ulnar corner of the lunate fossa and a line drawn perpendicular to the long axis of the radius, which averagely should be around $23^{\circ}$. RT, measured from the lateral film, is defined as the angle between a line joining the dorsal and palmar lips of the distal radial articular surface and a line drawn perpendicular to the long axis of the radius, which averagely should be around $11^{\circ}$ (palmar tilt). UV, measured from the PA film, is defined as the distance between two perpendiculars to the long axis of the radius, one from the ulnar corner of the lunate fossa and the other from the distal ulnar articular surface, which should be ulnar neutral in $60 \%$ of the population [18].

2.4. Patient Characteristics and Study Significance. We summarized the collected data at the time of study enrollment, which included demographic data, fracture types based on the AO/OTA classification system, surgical techniques, monthly radiographic assessments, and treatment complications such as nonunion, complex regional pain syndrome (CRPS), infection, or loosening. These data were analyzed to study the time course changes and patterns of fracture collapse and the causal relationship between surgical techniques and treatment outcomes. Results of this analysis may provide clues for refinement of surgical techniques and postoperative hand care program in future studies.

2.5. Statistical Analysis. A chi-square analysis or a Fisher's exact test was used when appropriate for analyzing categorical variables. For numerical variables, the nonparametric Wilcoxon rank sum test was used for between-group comparisons. Statistical significance was defined as $P<$ 0.05. All statistics were two-sided and performed using the Statistical Package for the Social Sciences (SPSS, v12.0; SPSS Inc., Chicago, Illinois).

\section{Results}

3.1. Analyses of Patient Characteristics and Related Variables. Eighty-five patients with displaced extra-articular fractures of the distal radius (AO/OTA type 23-A2.2 or 23-A3) were enrolled in this 4-year-long study. The mean patient age was 58.3 years (range $20-80$ ); twenty (23.5\%) were male, 
TABLE 1: Group comparison of patient characteristics and treatment complications.

\begin{tabular}{|c|c|c|c|}
\hline Variables & $\begin{array}{l}\text { Group } 1 \\
(n=25)\end{array}$ & $\begin{array}{l}\text { Group } 2 \\
(n=60)\end{array}$ & $P$ values ${ }^{\dagger}$ \\
\hline Mean age (yrs, range) & $54.7(20,80)$ & $59.9(24,76)$ & 0.095 \\
\hline Gender $(n, \%)$ & & & $0.235^{\ddagger}$ \\
\hline Male & $8(32)$ & $12(20)$ & \\
\hline Female & $17(68)$ & $48(80)$ & \\
\hline Side $(n, \%)$ & & & $1.000^{\ddagger}$ \\
\hline Right & $10(40)$ & $24(40)$ & \\
\hline Left & $15(60)$ & $36(60)$ & \\
\hline AO fracture type $(n, \%)$ & & & $0.160^{\ddagger}$ \\
\hline A2.2 & $6(24)$ & $24(40)$ & \\
\hline $\mathrm{A} 3$ & $19(76)$ & $36(60)$ & \\
\hline \multicolumn{4}{|l|}{ Complications $(n, \%)$} \\
\hline Nonunion & $0(0)$ & $0(0)$ & $1.000^{\ddagger}$ \\
\hline CRPS $^{\mathrm{a}}$ & $1(4)$ & $1(1.7)$ & $0.518^{\ddagger}$ \\
\hline Infection & $2(8)$ & $7(11.7)$ & $0.665^{\ddagger}$ \\
\hline Loosening & $4(16)$ & $13(21.7)$ & $0.552^{\ddagger}$ \\
\hline
\end{tabular}

${ }^{\dagger}$ Wilcoxon rank sum test, unless otherwise stated.

${ }^{\ddagger}$ Fischer's exact or chi-squared tests as applicable.

${ }^{\mathrm{a}}$ CRPS: complex regional pain syndrome.

and $65(76.5 \%)$ were female. $60 \%$ of fractures were the left wrist and $65 \%$ were type $23-\mathrm{A} 3$. All patients had undergone the above-mentioned techniques of percutaneous pinning for fracture reduction and pin fixation. Twenty-five (29.4\%) patients were treated with the modified Kapandji technique (group 1: Kapandji) and 60 treated with the Willenegger technique (group 2: Willenegger). Comparison of groups 1 and 2 revealed no significant differences in age, gender, involved lesion wrists, fracture types, and treatment complications such as nonunion, CRPS, infection, or loosening (all $P \geq 0.095$ ) (Table 1). There were no tendon or vascular complications and no dysfunction of the median nerve in this cohort.

3.2. Analyses of Radiographic Measurements before and after Fracture Reduction. All fractures in this cohort were diagnosed as displaced, meaning the fractured fragments were out of normal alignment. The mean $( \pm S D)$ RH, RI, RT, and UV values in groups 1 and 2 patients before fracture reduction were $9.63( \pm 2.84) \mathrm{mm}$ versus $8.76( \pm 2.31) \mathrm{mm}$ $(P=0.143), 20.00( \pm 5.37)$ degrees versus $18.63( \pm 4.43)$ degrees $(P=0.228),-17.64( \pm 12.81)$ degrees versus -19.01 $( \pm 9.81)$ degrees $(P=0.757)$, and $3.25( \pm 3.04) \mathrm{mm}$ versus $3.74( \pm 2.24) \mathrm{mm}(P=0.617)$, respectively. Attempts to manipulate the fractured fragments back into acceptable alignment were performed through the above-mentioned surgical techniques. The mean $( \pm \mathrm{SD}) \mathrm{RH}, \mathrm{RI}, \mathrm{RT}$, and UV values in groups 1 and 2 patients after fracture reduction were $11.82( \pm 2.32) \mathrm{mm}$ versus $12.13( \pm 1.80) \mathrm{mm}(P=0.510)$, $23.63( \pm 4.05)$ degrees versus $24.36( \pm 2.60)$ degrees $(P=$ $0.323), 2.06( \pm 5.78)$ degrees versus $3.78( \pm 4.35)$ degrees $(P=0.136)$, and $1.36( \pm 2.70) \mathrm{mm}$ versus $1.37( \pm 1.65) \mathrm{mm}$ $(P=0.996)$, respectively. Although there were no significant differences in the radiographic measurements before/after fracture reduction between the two groups, the reduction technique used in group 2 patients produced a more anatomic reduction in $\mathrm{RH}(2.20 \pm 2.32 \mathrm{~mm}$ versus $3.38 \pm 2.06 \mathrm{~mm}$, $P=0.010)$ and $\mathrm{RI}(3.64 \pm 2.59$ degrees versus $5.73 \pm 3.86$ degrees, $P=0.015$ ) compared to that used in group 1 patients (other $P \geq 0.136$ ) (Table 2 ).

3.3. Analyses of Radiographic Measurements after Fracture Fixation. In order to clarify the time course changes and patterns of fracture collapse after K-wire fixation in the two groups, we analyzed the radiographic measurements on the wrist films at follow-up. Comparison of groups 1 and 2 revealed no significant differences in all four measurements (RH, RI, RT, and UV) at one, two, three, and twelve months after percutaneous pinning (all $P \geq 0.136$ ) (Table 3 ). However, it seemed that there was a trend in both groups toward recurrent collapse in the first two months after fixation than thereafter (Figure 1). All fractures in this cohort were clinically and radiographically healed at the time of followup examinations three months after surgery. Further analyses on the monthly changes of radiographic measurements after fracture fixation revealed that the fixation technique used in group 1 patients produced less recurrent fracture collapse in month-1 RT $(3.06 \pm 6.51$ degrees versus $6.43 \pm 6.02$ degrees, $P=0.028)$ and month-2 RT $(0.63 \pm 1.89$ degrees versus $1.75 \pm 2.57$ degrees, $P=0.047)$ than that seen in group 2 patients. There were no significant differences in the monthly changes of other radiographic measurements between the two groups (all $P \geq 0.144$ ) (Table 4 ). When the final loss of alignment after fracture fixation was compared between the two groups, group 1 patients had significantly less loss of alignment in RT (3.78 \pm 7.09 degrees versus 8.39 \pm 6.74 degrees, 
TABLE 2: Group comparison of radiographic parameters before/after fracture reduction.

\begin{tabular}{|c|c|c|c|}
\hline Variables & $\begin{array}{l}\text { Group } 1 \\
(n=25)\end{array}$ & $\begin{array}{l}\text { Group } 2 \\
(n=60)\end{array}$ & $P$ values ${ }^{\dagger}$ \\
\hline \multicolumn{4}{|c|}{ Pre-op (mean, SD) } \\
\hline $\mathrm{RH}^{\mathrm{a}}(\mathrm{mm})$ & $9.63(2.84)$ & $8.76(2.31)$ & 0.143 \\
\hline $\mathrm{RI}^{\mathrm{b}}$ (degree) & $20.00(5.37)$ & $18.63(4.43)$ & 0.228 \\
\hline $\mathrm{RT}^{\mathrm{c}}$ (degree) & $-17.64(12.81)$ & $-19.01(9.81)$ & 0.757 \\
\hline $\mathrm{UV}^{\mathrm{d}}(\mathrm{mm})$ & $3.25(3.04)$ & $3.74(2.24)$ & 0.617 \\
\hline \multicolumn{4}{|c|}{ Post-op (mean, SD) } \\
\hline $\mathrm{RH}(\mathrm{mm})$ & $11.82(2.32)$ & $12.13(1.80)$ & 0.510 \\
\hline RI (degree) & $23.63(4.05)$ & $24.36(2.60)$ & 0.323 \\
\hline RT (degree) & $2.06(5.78)$ & $3.78(4.35)$ & 0.136 \\
\hline $\mathrm{UV}(\mathrm{mm})$ & $1.36(2.70)$ & $1.37(1.65)$ & 0.996 \\
\hline \multicolumn{4}{|c|}{$\Delta^{\mathrm{e}}$ Post-pre-op (mean, SD) } \\
\hline $\mathrm{RH}(\mathrm{mm})$ & $2.20(1.36)$ & $3.38(2.06)$ & $0.010^{*}$ \\
\hline RI (degree) & $3.64(2.59)$ & $5.73(3.86)$ & $0.015^{*}$ \\
\hline RT (degree) & $19.70(11.07)$ & $22.80(10.56)$ & 0.229 \\
\hline $\mathrm{UV}(\mathrm{mm})$ & $-2.07(2.55)$ & $-2.37(1.75)$ & 0.536 \\
\hline
\end{tabular}

${ }^{\dagger}$ Wilcoxon rank sum test, unless otherwise stated.

${ }^{*}$ The difference is significant $(P<0.05)$.

${ }^{\mathrm{a}} \mathrm{RH}$ : radial height; ${ }^{\mathrm{b}} \mathrm{RI}$ : radial inclination; ${ }^{\mathrm{c}} \mathrm{RT}$ : radial tilt; ${ }^{\mathrm{d}} \mathrm{UV}$ : ulnar variance; ${ }^{\mathrm{e}} \Delta Y_{2}-Y_{1}$ : change of $Y$.

TABLE 3: Group comparison of radiographic parameters after fracture fixation.

\begin{tabular}{|c|c|c|c|}
\hline Variables & $\begin{array}{l}\text { Group } 1 \\
(n=25)\end{array}$ & $\begin{array}{l}\text { Group } 2 \\
(n=60)\end{array}$ & $P$ values ${ }^{\dagger}$ \\
\hline \multicolumn{4}{|c|}{$\mathrm{RH}^{\mathrm{a}}(\mathrm{mm})($ mean, $\mathrm{SD})$} \\
\hline Post-op & $11.82(2.32)$ & $12.13(1.80)$ & 0.510 \\
\hline $\mathrm{M}^{\S}$ & $11.10(2.63)$ & $11.04(2.15)$ & 0.911 \\
\hline M2 & $10.86(2.76)$ & $10.76(2.22)$ & 0.856 \\
\hline M3 & $10.82(2.81)$ & $10.68(2.20)$ & 0.800 \\
\hline M12 & $10.84(2.49)$ & $10.65(2.18)$ & 0.674 \\
\hline \multicolumn{4}{|c|}{$\mathrm{RI}^{\mathrm{b}}$ (degree) (mean, SD) } \\
\hline Post-op & $23.63(4.05)$ & $24.36(2.60)$ & 0.323 \\
\hline M1 & $22.65(4.80)$ & $22.77(3.79)$ & 0.905 \\
\hline M2 & $22.48(4.93)$ & $22.52(3.80)$ & 0.962 \\
\hline M3 & $22.52(5.01)$ & $22.45(3.86)$ & 0.945 \\
\hline M12 & $22.48(4.95)$ & $22.42(3.85)$ & 0.724 \\
\hline \multicolumn{4}{|c|}{$\mathrm{RT}^{\mathrm{c}}$ (degree) (mean, SD) } \\
\hline Post-op & $2.06(5.78)$ & $3.78(4.35)$ & 0.136 \\
\hline M1 & $-1.00(8.62)$ & $-2.65(8.38)$ & 0.415 \\
\hline M2 & $-1.63(9.44)$ & $-4.40(9.16)$ & 0.212 \\
\hline M3 & $-1.72(8.94)$ & $-4.60(9.04)$ & 0.182 \\
\hline M12 & $-1.62(8.93)$ & $-4.58(8.94)$ & 0.154 \\
\hline \multicolumn{4}{|c|}{$\mathrm{UV}^{\mathrm{d}}(\mathrm{mm})($ mean, SD) } \\
\hline Post-op & $1.36(2.70)$ & $1.37(1.65)$ & 0.996 \\
\hline M1 & $2.34(2.35)$ & $2.73(2.02)$ & 0.446 \\
\hline M2 & $2.89(2.37)$ & $3.08(2.23)$ & 0.728 \\
\hline M3 & $3.23(2.49)$ & $3.21(2.23)$ & 0.976 \\
\hline M12 & $3.19(2.32)$ & $3.24(2.11)$ & 0.873 \\
\hline
\end{tabular}

${ }^{\dagger}$ Wilcoxon rank sum test, unless otherwise stated.

${ }^{\mathrm{a}} \mathrm{RH}$ : radial height; ${ }^{\mathrm{b}} \mathrm{RI}$ : radial inclination; ${ }^{\mathrm{c}} \mathrm{RT}$ : radial tilt; ${ }^{\mathrm{d}} \mathrm{UV}$ : ulnar variance.

${ }^{\S} \mathrm{M} x$ : $x$ months after the index surgery. 

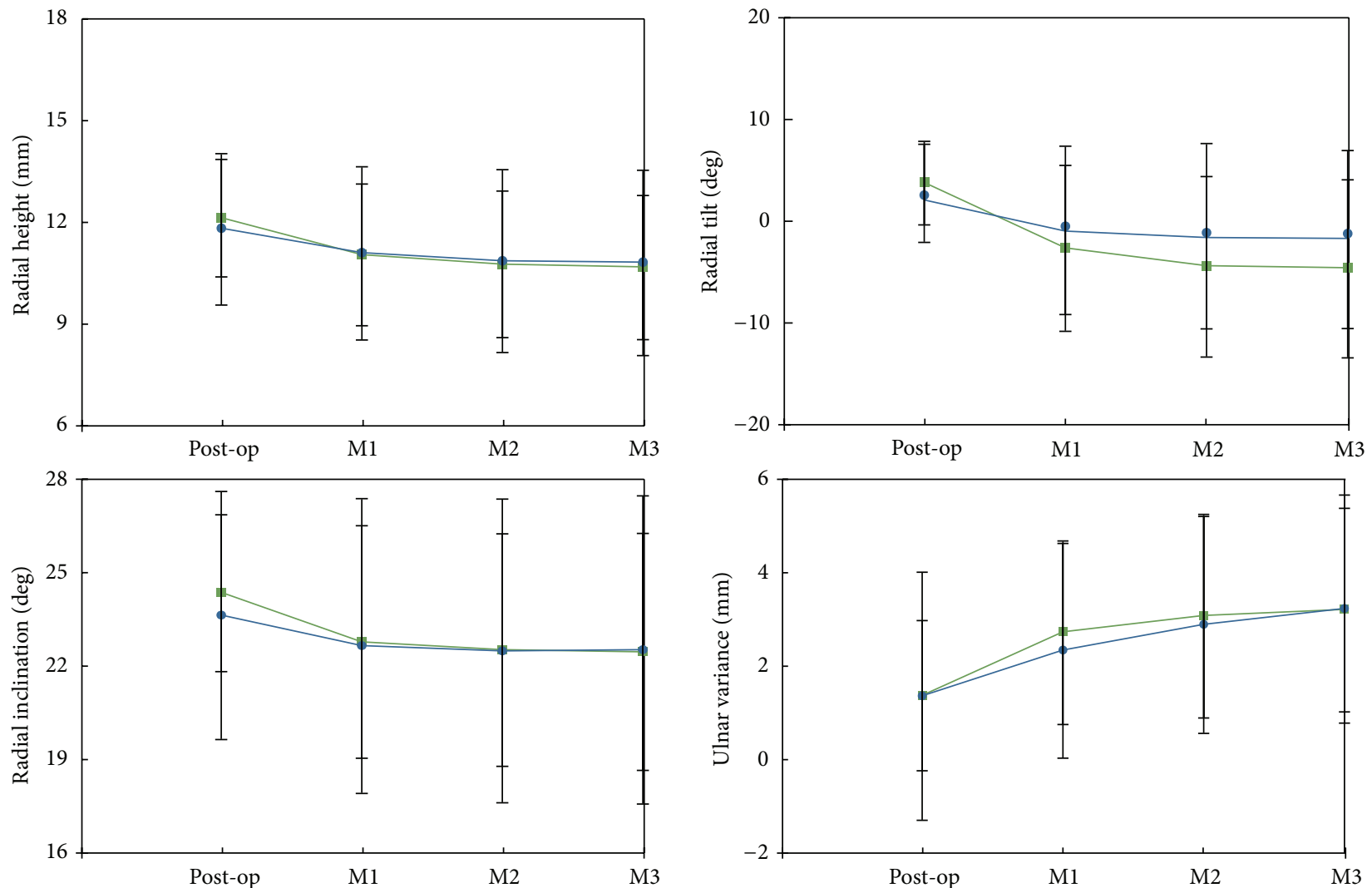

Kapandji

Kapandji

Conventional

Conventional

FIGURE 1: Group comparison of radiographic parameters after fracture fixation. Mx: $x$ months after the index surgery.

TABLE 4: Group comparison of time-dependent change of radiographic parameters after fracture fixation.

\begin{tabular}{|c|c|c|c|}
\hline Variables & $\begin{array}{l}\text { Group } 1 \\
(n=25)\end{array}$ & $\begin{array}{l}\text { Group } 2 \\
(n=60)\end{array}$ & $P$ values ${ }^{\dagger}$ \\
\hline \multicolumn{4}{|c|}{$\mathrm{RH}^{\mathrm{a}}(\mathrm{mm})($ mean, SD) } \\
\hline$\Delta^{\mathrm{e}}$ Post-M1 ${ }^{\S}$ & $0.72(0.96)$ & $1.10(1.63)$ & 0.292 \\
\hline$\Delta \mathrm{M} 1-\mathrm{M} 2$ & $0.24(0.77)$ & $0.28(0.69)$ & 0.882 \\
\hline$\Delta \mathrm{M} 2-\mathrm{M} 3$ & $0.04(0.52)$ & $0.08(0.46)$ & 0.723 \\
\hline \multicolumn{4}{|c|}{$\mathrm{RI}^{\mathrm{b}}$ (degree) (mean, SD) } \\
\hline$\Delta$ Post-M1 & $0.98(2.00)$ & $1.60(3.02)$ & 0.354 \\
\hline$\Delta \mathrm{M} 1-\mathrm{M} 2$ & $0.17(1.23)$ & $0.24(1.10)$ & 0.798 \\
\hline$\Delta \mathrm{M} 2-\mathrm{M} 3$ & $-0.04(0.79)$ & $0.07(0.85)$ & 0.557 \\
\hline \multicolumn{4}{|c|}{$\mathrm{RT}^{\mathrm{c}}$ (degree) (mean, SD) } \\
\hline$\Delta$ Post-M1 & $3.06(6.51)$ & $6.43(6.02)$ & $0.028^{*}$ \\
\hline$\Delta \mathrm{M} 1-\mathrm{M} 2$ & $0.63(1.89)$ & $1.75(2.57)$ & $0.047^{*}$ \\
\hline$\Delta \mathrm{M} 2-\mathrm{M} 3$ & $0.09(1.34)$ & $0.21(1.24)$ & 0.547 \\
\hline \multicolumn{4}{|c|}{$\mathrm{UV}^{\mathrm{d}}(\mathrm{mm})($ mean, SD) } \\
\hline$\Delta$ Post-M1 & $-0.98(1.25)$ & $-1.36(1.23)$ & 0.237 \\
\hline$\Delta \mathrm{M} 1-\mathrm{M} 2$ & $-0.55(0.76)$ & $-0.35(0.65)$ & 0.227 \\
\hline$\Delta \mathrm{M} 2-\mathrm{M} 3$ & $-0.34(0.78)$ & $-0.14(0.47)$ & 0.144 \\
\hline
\end{tabular}

${ }^{\dagger}$ Wilcoxon rank sum test, unless otherwise stated.

${ }^{*}$ The difference is significant $(P<0.05)$.

${ }^{\mathrm{a}} \mathrm{RH}$ : radial height; ${ }^{\mathrm{b}} \mathrm{RI}$ : radial inclination; ${ }^{\mathrm{c}} \mathrm{RT}$ : radial tilt; ${ }^{\mathrm{d}} \mathrm{UV}$ : ulnar variance; ${ }^{\mathrm{e}} \Delta Y_{2}-Y_{1}$ : change of $Y$.

${ }^{\S} \mathrm{M} x: x$ months after the index surgery. 
TABLE 5: Group comparison of the final loss of alignment after fracture healing.

\begin{tabular}{lccc}
\hline Variables & $\begin{array}{c}\text { Group 1 } \\
(n=25)\end{array}$ & $\begin{array}{l}\text { Group 2 } \\
(n=60)\end{array}$ & $P$ values $^{\dagger}$ \\
\hline$\Delta^{\mathrm{e}}$ Post-M3 $($ mean, SD) & & & \\
$\mathrm{RH}^{\mathrm{a}}(\mathrm{mm})$ & $1.00(1.31)$ & $1.45(1.67)$ & 0.305 \\
$\mathrm{RI}^{\mathrm{b}}($ degree $)$ & $1.11(2.46)$ & $1.91(3.21)$ & 0.267 \\
$\mathrm{RT}^{\mathrm{c}}($ degree $)$ & $3.78(7.09)$ & $8.39(6.74)$ & $0.006^{*}$ \\
$\mathrm{UV}^{\mathrm{d}}(\mathrm{mm})$ & $-1.85(1.44)$ & $-1.85(1.44)$ & 0.958 \\
\hline
\end{tabular}

${ }^{\dagger}$ Wilcoxon rank sum test, unless otherwise stated.

${ }^{*}$ The difference is significant $(P<0.05)$.

${ }^{\mathrm{a}} \mathrm{RH}$ : radial height; ${ }^{\mathrm{b}} \mathrm{RI}$ : radial inclination; ${ }^{\mathrm{c}} \mathrm{RT}$ : radial tilt; ${ }^{\mathrm{d}} \mathrm{UV}$ : ulnar variance; ${ }^{\mathrm{e}} \Delta Y_{2}-Y_{1}$ : change of $Y$.

${ }^{\S} \mathrm{M} x: x$ months after the index surgery.

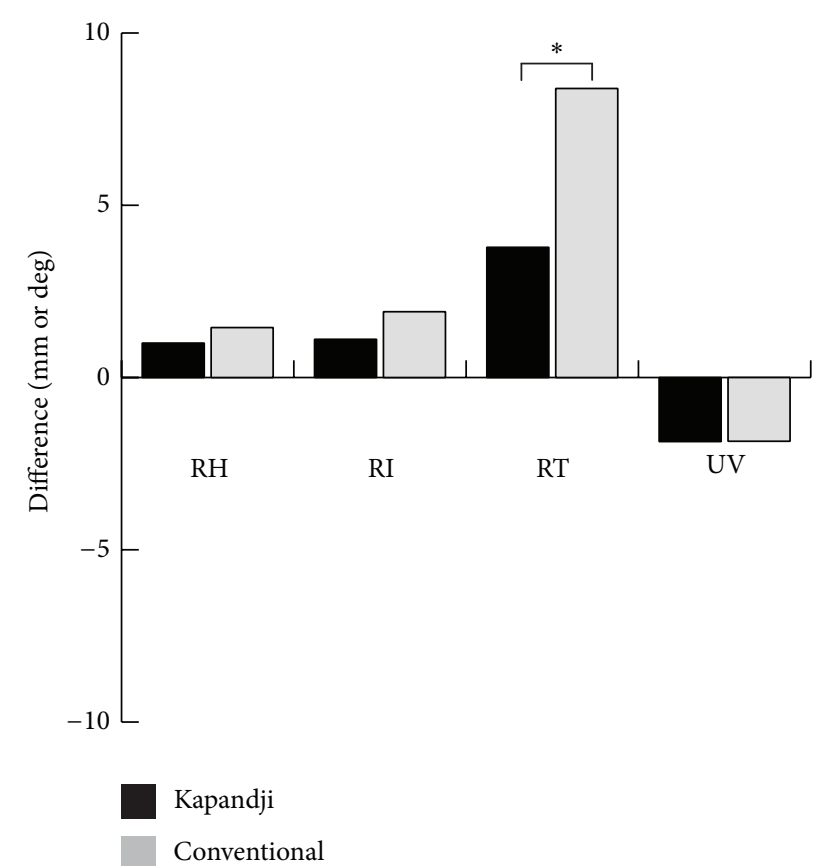

FIGURE 2: Group comparison of the final loss of alignment after fracture fixation. RH: radial height; RI: radial inclination; RT: radial tilt; UV: ulnar variance; ${ }^{*}$ denotes that the difference is significant $(P<0.05)$ by Wilcoxon rank sum test.

$P=0.006)$ than group 2 patients. Although there was a trend toward a better maintenance of global alignment in group 1 patients, this was not statistically significant in RH, RI, and UV (all $P \geq 0.267$ ) (Table 5 and Figure 2).

\section{Discussion}

Although there are myriad factors that affect patient satisfaction following a distal radius fracture, the main treatment objectives are (1) to achieve and maintain the reduced anatomic alignment until bone healing; (2) to decrease associated wrist pain; and (3) to encourage early joint motion [1-7, 19]. Conventional pinning (Willenegger) technique remains a key method of percutaneous pinning for displaced distal radius fractures [9]; however, the reliability of achievement and maintenance of the reduced position until bone healing is always a concern $[13,14,16,17]$. Kapandji advocated and popularized the technique of intrafocal manipulation and pinning with improving stability and allowing unprotected early motion immediately after surgery $[10,11]$. With this technique, Epinette et al. reported $83 \%$ of excellent and good results in their case series [20]. Although promising, others found in their prospective studies that there was an increased frequency of pin related complications after Kapandji pinning when compared to that after Willenegger pinning [21-24]. We therefore modified the original Kapandji technique (intrafocal manipulation and transfocal, not intrafocal, fixation) in our clinical practice to decrease skin indentation, tethering, and/or other intrafocal-pin related complications. Our results in this study revealed that there was a trend toward a decrease in frequency of complications in patients treated by the modified Kapandji technique compared with those treated by the Willenegger pinning method, although the differences were not statistically significant.

Our study showed that early fracture collapse occurred in patients with a displaced extra-articular distal radius fracture treated by percutaneous pinning and early mobilization. However, the final radiographic results of the two methods which we studied were both described as acceptable in terms of the four radiographic measurements according to the criteria of Graham [7]. Compared with the Willenegger method, the modified Kapandji technique achieved a less but adequate initial restoration of RH/RI and provided a better maintenance of the reduced position until bone healing. The key of the modified Kapandji technique for improved maintenance of the reduced anatomic alignment is supposed to be the combination of intrafocal manipulation and cross-pin transfocal fixation. Intrafocal manipulation provides a sufficient realignment and a good contact at the fracture surface while avoiding overtraction of the fracture site and undue stress concentration in the implant [25]. Cross-pin transfocal fixation provides a great resistance to gross rotational displacement and prevents the intrafocalpin related complications such as implant impingement pain, stiffness, CRPS, infection, loosening, or nonunion [26, 27]. The postoperative hand care regimen used in this study permits early wrist and hand mobilization, which is now moderately recommended by the AAOS [8].

Among the radiographic measurements, the palmar RT was the most difficult to achieve and to maintain when repositioning and pinning the fractured fragments and realigning 
the radial geometry. Normal palmar RT should average about 11 degrees [18]. However, none of the two techniques we used in this study was reliable in restoring the long term normal palmar RT even in the presence of conventionally acceptable radiographic results. The techniques of closed reduction usually depend on ligamentotaxis to restore the RT. Bartosh and Saldana found that when traction is applied across the wrist, the palmar radiocarpal ligaments, which are short and tough, tighten first and then pull on the distal fragment before the thinner dorsal radiocarpal ligaments exert any traction, thus limiting the ability of closed reduction techniques to restore the normal palmar RT $[16,28]$. It is interesting that the intrafocal reduction technique did not achieve a better restoration of the $\mathrm{RT}$ than that assisted by Chinese finger traps. Even though a higher percentage of AO/OTA type 23A3 fractures in group 1 patients $(76 \%$ versus $60 \%, P=0.160)$ may explain this observation, we recommend that further refinement of surgical techniques and postoperative hand care program may be necessary in future clinical practices and studies.

Several limitations of this study are noted. First, a weakness is its retrospective nature with the inherent limitations of such a study design. Second, there is lack of functional outcome measurements in this investigation. For treatment of displaced extra-articular fractures of the distal radius, percutaneous pinning techniques have been welldocumented surgical methods with distinct correlations between the functional results and the radiographic outcome measures $[1-7,19]$. The purpose of this retrospective study was therefore to determine the effects of different methods on the maintenance of the reduced position until bone healing, leaving functional outcome considerations aside. Finally, only AO/OTA type $23-\mathrm{A} 2.2$ or $23-\mathrm{A} 3$ fractures were included. Catalano et al. had found that the final functional results do not correlate with the magnitude of the residual step and gap displacement at the time of fracture healing [29]. In order to minimize systemic errors and bias, we excluded all intra-articular fractures of the distal radius in the current work.

\section{Conclusions}

For displaced extra-articular fractures of the distal radius treated with percutaneous pinning, our time course study revealed that early fracture collapse with loss of the reduced RT occurred. Besides, among the 4 measurements, the normal RT was the most difficult to be achieved when repositioning and pinning the fractured fragments. The modified Kapandji technique provided a superior ability to maintain the reduced position until bone healing over the Willenegger pinning. The intrafocal manipulation may create a good stable contact at the fracture surface, whereas the cross-pin transfocal fixation may provide a great resistance to displacement and may prevent intrafocal-pin related complications. Even though the results are promising, we recommended that refinement of surgical techniques and postoperative hand care program may be necessary to fulfill the treatment objectives of stable surgical fixation and early joint motion.

\section{Conflict of Interests}

The authors declare that there is no conflict of interests regarding the publication of this paper.

\section{References}

[1] H. T. Aro and T. Koivunen, "Minor axial shortening of the radius affects outcome of Colles' fracture treatment," Journal of Hand Surgery A, vol. 16, no. 3, pp. 392-398, 1991.

[2] J. Taleisnik and H. K. Watson, "Midcarpal instability caused by malunited fractures of the distal radius," Journal of Hand Surgery A, vol. 9, no. 3, pp. 350-357, 1984.

[3] B. D. Adams, "Effects of radial deformity on distal radioulnar joint mechanics," Journal of Hand Surgery A, vol. 18, no. 3, pp. 492-498, 1993

[4] H. Kihara, A. K. Palmer, F. W. Werner, W. H. Short, and M. D. Fortino, "The effect of dorsally angulated distal radius fractures on distal radioulnar joint congruency and forearm rotation," Journal of Hand Surgery A, vol. 21, no. 1, pp. 40-47, 1996.

[5] M. McQueen and J. Caspers, "Colles fracture: does the anatomical result affect the final function?" Journal of Bone and Joint Surgery B, vol. 70, no. 4, pp. 649-651, 1988.

[6] N. H. Jenkins and W. J. Mintowt-Czyz, "Mal-union and dysfunction in Colles' fracture," Journal of Hand Surgery B, vol. 13, no. 3, pp. 291-293, 1988.

[7] T. J. Graham, "Surgical correction of malunited fractures of the distal radius," Journal of the American Academy of Orthopaedic Surgeons, vol. 5, no. 5, pp. 270-281, 1997.

[8] D. M. Lichtman, R. R. Bindra, M. I. Boyer et al., "Treatment of distal radius fractures," Journal of the American Academy of Orthopaedic Surgeons, vol. 18, no. 3, pp. 180-189, 2010.

[9] H. H. Handoll, M. V. Vaghela, and R. Madhok, "Percutaneous pinning for treating distal radial fractures in adults," Cochrane Database of Systematic Reviews, no. 3, Article ID CD006080, 2007.

[10] A. Kapandji, "Intra-focal pinning of fractures of the lower extremity of the radius. Ten years after," Annales de Chirurgie de la Main, vol. 6, no. 1, pp. 57-63, 1987.

[11] M. D. Greatting and A. T. Bishop, "Intrafocal (Kapandji) pinning of unstable fractures of the distal radius," Orthopedic Clinics of North America, vol. 24, no. 2, pp. 301-307, 1993.

[12] H. Willenegger and A. Guggenbühl, "Operative treatment of certain cases of distal radius fracture," Helvetica Chirurgica Acta, vol. 26, no. 2, pp. 81-94, 1959.

[13] G. J. Clancey, "Percutaneous Kirschner-wire fixation of Colles fractures: a prospective study of thirty cases," Journal of Bone and Joint Surgery A, vol. 66, no. 7, pp. 1008-1014, 1984.

[14] E. T. Mah and R. N. Atkinson, "Percutaneous Kirschner wire stabilisation following closed reduction of Colles' fractures," Journal of Hand Surgery B, vol. 17, no. 1, pp. 55-62, 1992.

[15] J. Allain, P. Le Guilloux, S. Le Mouël, and D. Goutallier, “Transstyloid fixation of fractures of the distal radius. A prospective randomized comparison between 6- and 1-week postoperative immobilization in 60 fractures," Acta Orthopaedica Scandinavica, vol. 70, no. 2, pp. 119-123, 1999.

[16] M. M. McQueen, "Redisplaced unstable fractures of the distal radius," Journal of Bone and Joint Surgery B, vol. 80, no. 4, pp. 665-669, 1998.

[17] M. J. Botte, J. L. W. Davis, B. A. Rose et al., "Complications of smooth pin fixation of fractures and dislocations in the hand 
and wrist," Clinical Orthopaedics and Related Research, no. 276, pp. 194-201, 1992.

[18] D. A. Richly and D. A. Campbell, "Distal radius and wrist," in AO Principles of Fracture Management, T. P. Rüedi, R. E. Buckley, and C. G. Moran, Eds., vol. 2, p. 660, Thieme, New York, NY, USA, 2nd edition, 2007.

[19] D. J. Slutsky, "Predicting the outcome of distal radius fractures," Hand Clinics, vol. 21, no. 3, pp. 289-294, 2005.

[20] J. A. Epinette, J. M. Lehut, M. Cavenaile, J. C. Bouretz, and J. Decoulx, "Pouteau-Colles fracture: double-closed "basket-like" pinning according to Kapandji. Apropos of a homogeneous series of 70 cases," Annales de Chirurgie de la Main, vol. 1, no. 1, pp. 71-83, 1982.

[21] E. Lenoble, C. Dumontier, D. Goutallier, and A. Apoil, "Fracture of the distal radius. A prospective comparison between transstyloid and Kapandji fixations," Journal of Bone and Joint Surgery $B$, vol. 77, no. 4, pp. 562-567, 1995.

[22] P. C. Strohm, C. A. Müller, T. Boll, and U. Pfister, "Two procedures for kirschner wire osteosynthesis of distal radial fractures: a randomized trial," Journal of Bone and Joint Surgery A, vol. 86, no. 12, pp. 2621-2628, 2004.

[23] D. V. C. Stoffelen and P. L. Broos, "Kapandji pinning or closed reduction for extra-articular distal radius fractures," Journal of Trauma-Injury, Infection and Critical Care, vol. 45, no. 4, pp. 753-757, 1998.

[24] D. G. Hargreaves, S. J. Drew, and R. Eckersley, "Kirschner wire pin tract infection rates: a randomized controlled trial between percutaneous and buried wires," Journal of Hand Surgery B, vol. 29, no. 4, pp. 374-376, 2004.

[25] J. K. Oh, D. Sahu, Y. H. Ahn et al., "Effect of fracture gap on stability of compression plate fixation: a finite element study," Journal of Orthopaedic Research, vol. 28, no. 4, pp. 462-467, 2010.

[26] R. Gravier, X. Flecher, S. Parratte, P. Rapaie, and J. N. Argenson, "Trans-styloid and intrafocal pinning for extra-articular extension fractures of the distal radius: prospective randomized postoperative comparison with simple intra-focal pinning," Revue de Chirurgie Orthopédique et Réparatrice de l'Appareil Moteur, vol. 92, no. 7, pp. 657-662, 2006.

[27] L. E. Zionts, H. A. McKellop, and R. Hathaway, "Torsional strength of pin configurations used to fix supracondylar fractures of the humerus in children," Journal of Bone and Joint Surgery A, vol. 76, no. 2, pp. 253-256, 1994.

[28] R. A. Bartosh and M. J. Saldana, "Intraarticular fractures of the distal radius: a cadaveric study to determine if ligamentotaxis restores radiopalmar tilt," Journal of Hand Surgery A, vol. 15, no. 1, pp. 18-21, 1990.

[29] L. W. Catalano III, R. J. Cole, R. H. Gelberman, B. A. Evanoff, L. A. Gilula, and J. Borrelli Jr., "Displaced intra-articular fractures of the distal aspect of the radius: long-term results in young adults after open reduction and internal fixation," Journal of Bone and Joint Surgery A, vol. 79, no. 9, pp. 1290-1302, 1997. 


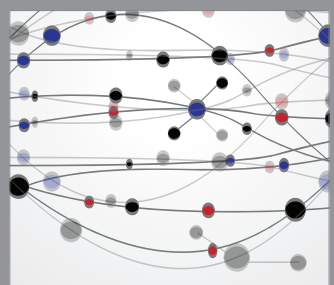

The Scientific World Journal
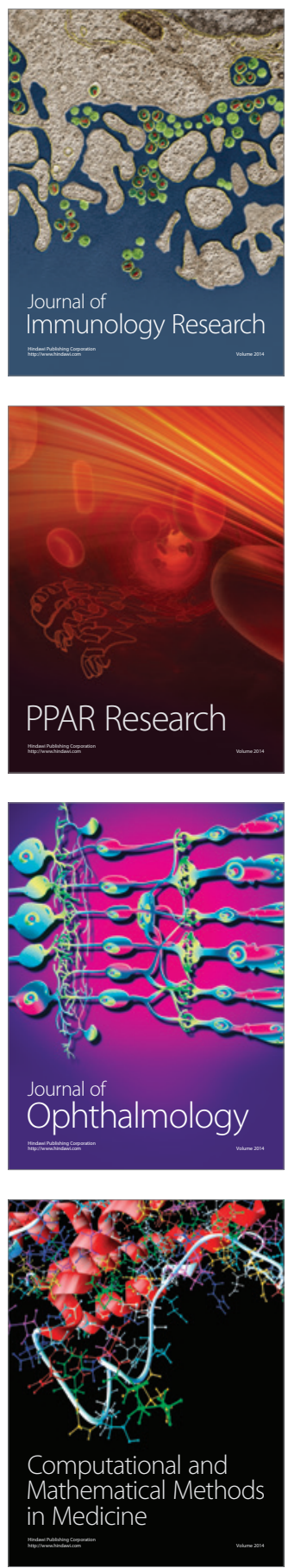

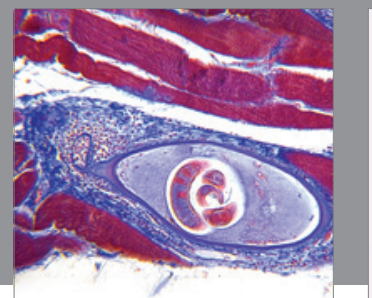

Gastroenterology

Research and Practice
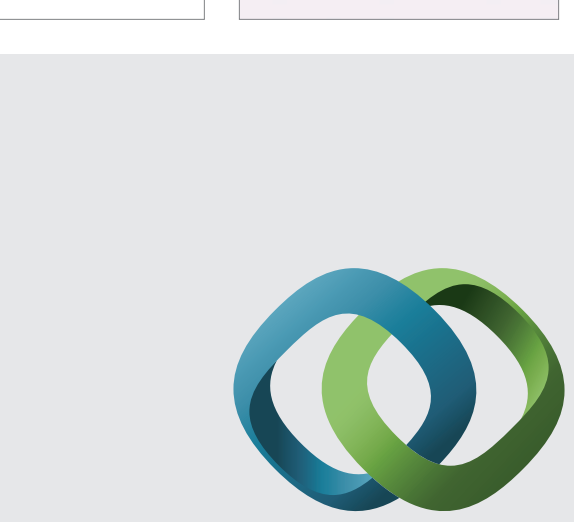

\section{Hindawi}

Submit your manuscripts at

http://www.hindawi.com
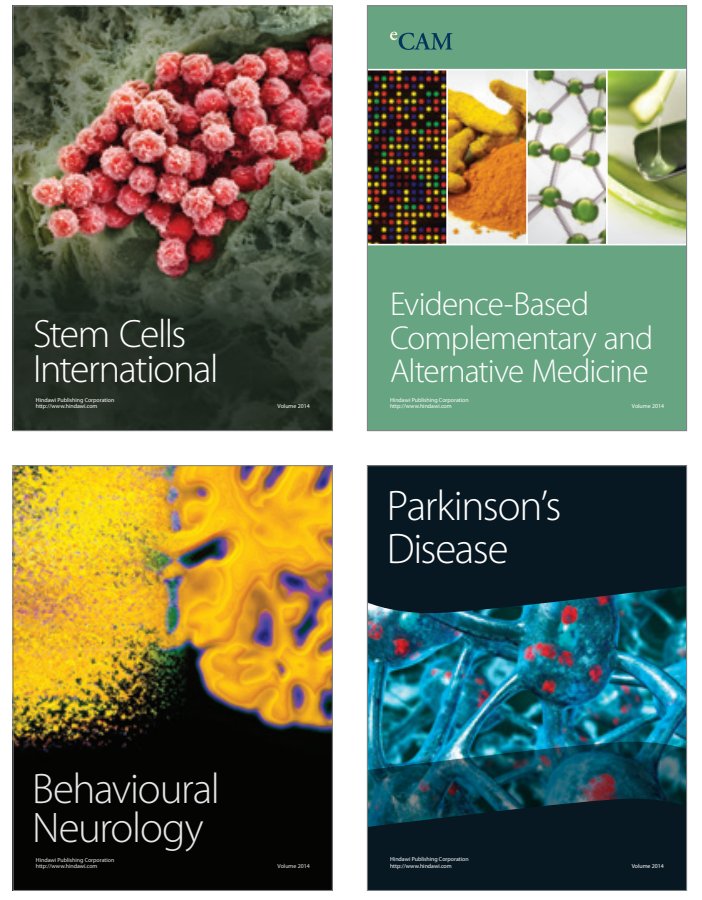
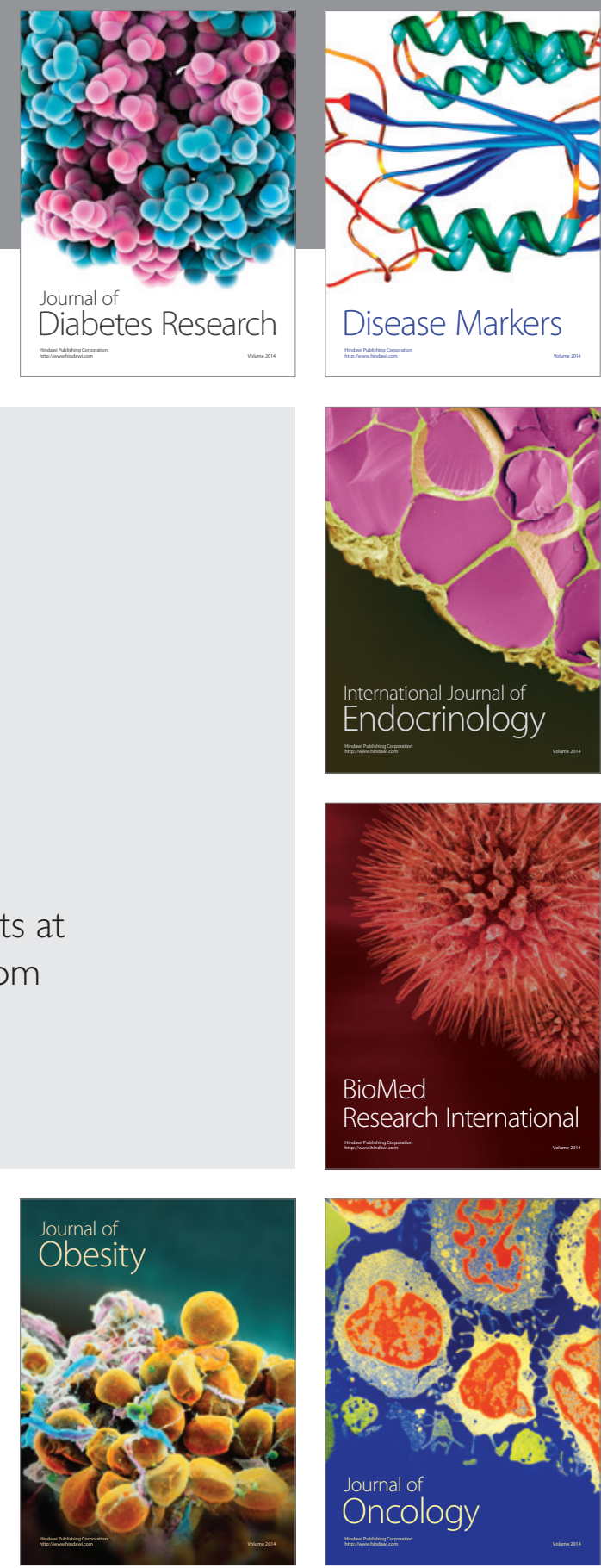

Disease Markers
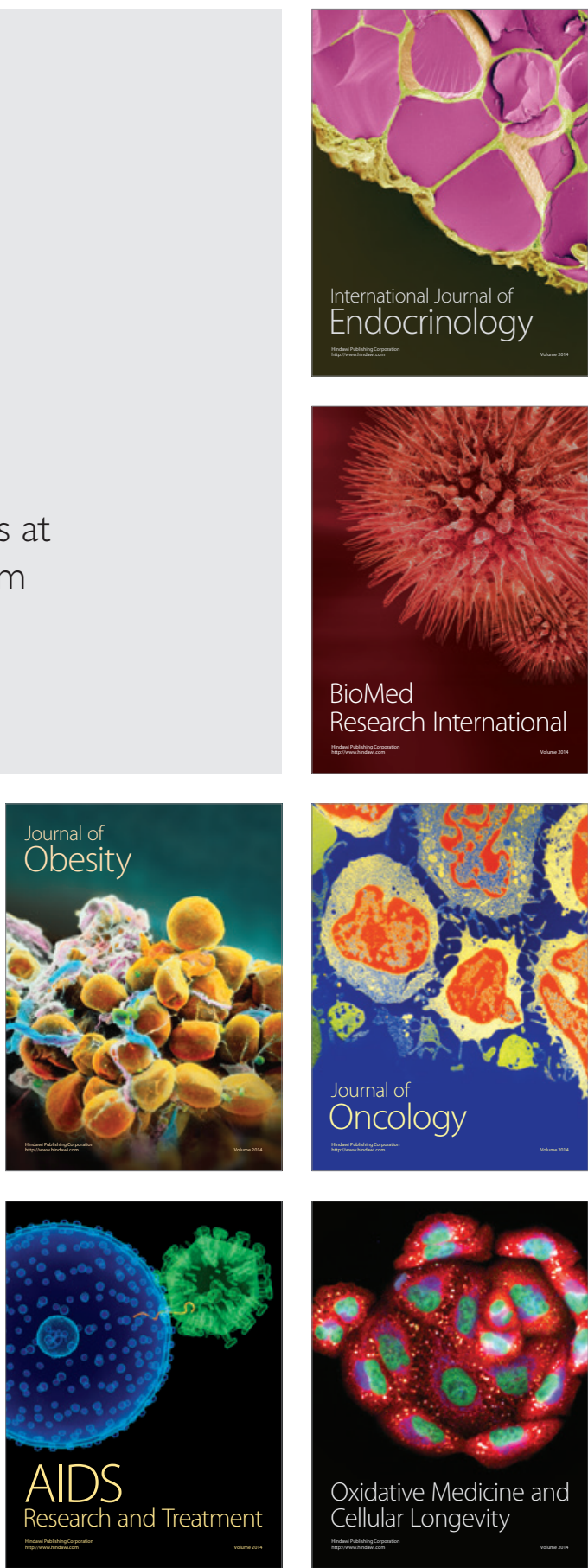